LLNL Contribution to Sandia Used Fuel Disposition - Security March 2011 Deliverable

J. A. Blink

March 25, 2011 
This document was prepared as an account of work sponsored by an agency of the United States government. Neither the United States government nor Lawrence Livermore National Security, LLC, nor any of their employees makes any warranty, expressed or implied, or assumes any legal liability or responsibility for the accuracy, completeness, or usefulness of any information, apparatus, product, or process disclosed, or represents that its use would not infringe privately owned rights. Reference herein to any specific commercial product, process, or service by trade name, trademark, manufacturer, or otherwise does not necessarily constitute or imply its endorsement, recommendation, or favoring by the United States government or Lawrence Livermore National Security, LLC. The views and opinions of authors expressed herein do not necessarily state or reflect those of the United States government or Lawrence Livermore National Security, LLC, and shall not be used for advertising or product endorsement purposes.

This work performed under the auspices of the U.S. Department of Energy by Lawrence Livermore National Laboratory under Contract DE-AC52-07NA27344. 
Add sections on material attractiveness, NAS spent fuel standard, threat evolution.

\section{Material Attractiveness}

\section{Proliferation Pathway Stages}

Cleary [2007] divides the proliferation pathway into stages: diversion, facility misuse, transportation, transformation, and weapons fabrication. King [2010], using Cleary's methodology, compares a deepburn fusion-driven blanket containing weapons-grade plutonium with a PWR burning MOX fuel enrichments of 5-9\%. King [2010] considers the stages of theft, transportation, transformation, and nuclear explosive fabrication.

In the current study of used fuel storage security, a similar approach is appropriate. First, one must consider the adversary's objective, which can be categorized as on-site radionuclide dispersion, theft of material for later radionuclide dispersion, and theft of material for later processing and fabrication into a nuclear explosive.

For on-site radionuclide dispersion, only a single proliferation pathway stage is appropriate: dispersion. That situation will be addressed in future reports.

For later radionuclide dispersion, the stages are theft (by an outsider or by facility misuse by an insider), transportation, and transformation (from oxide spent fuel containing both fission products and actinides to a material size and shape suitable for dispersion).

For later processing and fabrication into a nuclear explosive, the stages are theft (by an outsider or by facility misuse by an insider), transportation, transformation (from oxide spent fuel containing both fission products and actinides to a metal alloy), and fabrication (of the alloy into a weapon). It should be noted that the theft and transportation stages are similar, and possibly identical, for later radionuclide dispersion and later processing and fabrication into a nuclear explosive.

Each stage can be evaluated separately, and the methodology can vary for each stage. For example, King [2010] starts with the methodology of Cleary for the theft, transportation, transformation, and fabrication stages. Then, for each stage, King [2010] assembles and modifies the attributes and inputs suggested by Cleary.

In the theft (also known as diversion) stage, Cleary [2007] has five high-level categories (material handling during diversion, difficulty of evading detection by the accounting system, difficulty of evading detection by the material control system, difficulty of conducting undeclared facility modifications for the purpose of diverting nuclear material, and difficulty of evading detection of the facility modifications for the purposes of diverting nuclear material). Each category has one or more subcategories. For example, the first category includes mass per significant quantity (SQ) of nuclear material, volume/SQ of nuclear material, number of items/SQ, material form (solid, liquid, powder, gas), radiation level in terms of dose, chemical reactivity, heat load, and process temperature. King [2010] adds the following two subcategories to that list: SQs available for theft, and interruptions/changes (normal and unexpected) in material stocks and flows. For the situation of an orphaned surface storage facility, this approach is applicable, with some of the categories and subcategories being modified to reflect the static situation (no additions or removals of fuel or containers). In addition, theft would require opening a large overpack and either removing a full container or opening that sealed container and then removing one or more spent nuclear fuel assemblies. These activities would require time without observation (detection), heavy-duty equipment, and some degree of protection of the thieves from radiological dose.

In the transportation stage, Cleary [2007] has two high-level categories (difficulty of handling material during transportation, and difficulty of evading detection during transport). Each category has a number of subcategories. For the situation of an orphaned surface storage facility, these categories are applicable. 
The transformation stage of Cleary [2007] has three high-level categories (facilities and equipment needed to process diverted materials; knowledge, skills, and workforce needed to process diverted materials; and difficulty of evading detection of transformation activities). Again, there are subcategories. King [2007] adds a fourth high-level category: time required to transform the materials. For the situation of an orphaned surface storage facility, the categories are applicable, but the evaluations of each category and subcategory will be significantly different for later radionuclide dispersion than for later processing and fabrication into a nuclear explosive.

The fabrication stage of Cleary [2007] has three high-level categories (difficulty associated with design, handling difficulties, and knowledge and skills needed to design and fabricate). King [2010] replaces the first two high-level categories with the Figure of Merit for Nuclear Explosives Utility (FOM), with subcategories of bare critical mass, heat content of transformed material, dose rate of transformed material, and SQs available for theft. The next section of this report describes the FOM in more detail.

\section{Material Attractiveness: Figure of Merit}

Material attractiveness is a metric that describes the weapons utility of processed (transformed) nuclear material, for safeguards and security purposes, in an unclassified environment. Material attractiveness is a calculated number, a Figure of Merit, or FOM [Bathke, 2009a; Bathke, 2009b; Sleaford, 2010; King, 2010].

As shown in Equation 1, the FOM is defined [Sleaford 2010] as

Equation 1:

$$
F O M=1-\log _{10}\left(\frac{M}{800}+\frac{M \bullet h}{4500}+\frac{N}{10}\left[\frac{D}{500}\right]^{\frac{1}{\log _{10} 2}}\right)
$$

The FOM is an empirically derived formula that uses two physical parameters associated with the product material that is to be weaponized, i.e., the metal alloy produced in the transformation stage that is the starting point for the fabrication stage. These two parameters are the bare critical mass, $\mathrm{M}$, in $\mathrm{kg}$ and the heat content, $\mathrm{h}$, in $\mathrm{W} / \mathrm{kg}$. The third parameter in the equation is the dose rate, $\mathrm{D}$, in $\mathrm{rad} / \mathrm{h}$; it could be calculated for the material before or after transformation, depending on what stage of the proliferation pathway is being evaluated. The term with the dose rate also includes the net weight of the item, $\mathrm{N}$, in $\mathrm{kg}$. The net weight for the theft stage would be the spent fuel assembly weight; whereas, the net weight for the fabrication stage is the weight of the component being handled.

The values of the constants and exponents in the FOM are designed to produce a range nominally between zero and three. FOM values less than 1.0 represent materials that are impractical for weapons utility (low or very low Materials Attractiveness, and Attractiveness Levels D or E from the DOE manual [DOE, 2006b]). FOM values greater than 2.0 represent materials preferred for nuclear explosive fabrication (high Materials Attractiveness, and Attractiveness Level B from DOE [2006b]). Intermediate values between 1.0 and 2.0 are potentially usable (medium Materials Attractiveness, and Attractiveness Level C from DOE [2006b]).

The argument of the logarithm of the FOM is the overall complexity of the material. Lower complexity increases the FOM due to the negative sign on the logarithm, and use of a logarithm converts large differences into a more comprehensible and manageable scale. The constant term from which the logarithm is subtracted is set to 1.0 so that the FOM is 1.0 when the material complexity is 1.0 .

The first argument of the complexity is the size factor. It is based on $\mathrm{M}$, the bare critical mass of the transformed material that is required to build a nuclear explosive. In general, as $\mathrm{M}$ increases, the required amount of source material increases. It becomes impractical to build the device when $\mathrm{M}$ becomes very 
large. The reference point for this impracticality has historically been set at $20 \%{ }^{235} \mathrm{U}$ enrichment, which has a bare critical mass of about $800 \mathrm{~kg}$. At the reference point, the size factor is 1.0 (leading to a zero logarithm and an FOM of 1.0 for that $\mathrm{M}$ when the other terms are ignored). An M of $80 \mathrm{~kg}$ (10x lower) would lead to an FOM of 2.0 when the other terms are ignored.

The second argument of the complexity is the stability factor. It is based on $\mathrm{M}$ and the heat content, h, in $\mathrm{W} / \mathrm{kg}$. The constant of $4500 \mathrm{~W}$ is based on radioisotope thermal generators (RTG), which use the decay heat of ${ }^{238} \mathrm{Pu}$. An $80 \%: 20 \%$ mixture of ${ }^{238} \mathrm{Pu}:{ }^{239} \mathrm{Pu}$ has $\mathrm{M}=9.6 \mathrm{~kg}$ and $\mathrm{h}=412 \mathrm{~W} / \mathrm{kg}$. At these values, the stability factor is 1.0 , resulting in an FOM value of 1.0 for that heat content when the other terms are ignored. An $8 \%: 92 \%$ mixture of ${ }^{238} \mathrm{Pu}:{ }^{239} \mathrm{Pu}$ has $\mathrm{M}=10 \mathrm{~kg}$ and $\mathrm{h}=43 \mathrm{~W} / \mathrm{kg}$ (a stability factor $10 \mathrm{x}$ lower), resulting in an FOM of 2.0 when the other terms are ignored.

The third argument of the complexity is the acquisition factor. It is based on the acute dose rate, $\mathrm{D}$, in $\mathrm{rad} / \mathrm{h}$. The dose rate used to evaluate the FOM should be consistent with the material at the stage of the proliferation pathway being considered. For the fabrication stage, it is the product material, whereas for the theft stage for an orphaned surface storage site, it is the spent nuclear fuel assembly. The dose rate is that at $1 \mathrm{~m}$ from the material, with no intervening shielding. The constant of $500 \mathrm{rad} / \mathrm{hr}$ is equivalent to $5000 \mathrm{rad} / \mathrm{hr}$ at a more realistic working distance of $30 \mathrm{~cm}$ for the fabrication stage. (For the theft stage in an orphaned surface storage site, we may need to change the constant to a higher value based on working with heavy equipment and being farther away from the material.) Nominally, 5000 rad results in 100\% incapacitation within one hour and 50\% incapacitation within 30 minutes. For D = 500 rad/hr, the dose rate multiplicative contribution to the acquisition factor is 1.0, resulting in an FOM value of 1.0 when the other terms are ignored. The exponent is designed to change the dose rate contribution by $10 \mathrm{x}$ (or the single-term FOM by 1.0) when the dose rate changes by $2 \mathrm{x}$. For example, a dose rate of $250 \mathrm{rad} / \mathrm{hr}$ results in a single-term FOM of 2.0.

The acquisition factor is modified to account for the net weight, $\mathrm{N}$, of the item in $\mathrm{kg}$. The heavier or larger the item, the more difficult it is to steal or divert. A 10x change in net weight results in a change in FOM by one unit. For example, the single-term FOM is zero in the fabrication stage for a net weight of $100 \mathrm{~kg}$ and a dose rate of $500 \mathrm{rad} / \mathrm{h}$. If the item is very small, or the net weight is not known, one can evaluate Equation 1 using $\mathrm{N}=\mathrm{M} / 5$. A net weight constant of $10 \mathrm{~kg}$ is appropriate for the fabrication stage, but we may need to change the reference values of both the dose rate and the net weight for the theft stage at an orphaned surface storage site.

\section{Material Attractiveness: Use in this Study}

Nuclear weapons experts at both LANL and LLNL reviewed the FOM. While it was determined that there are a number of smaller factors that are not captured, it was agreed that the FOM adequately captures the dominant factors in an unclassified format.

The FOM represents an important part of the overall proliferation and security risks that are posed by various materials and processes in the nuclear fuel cycle. To contextualize the FOM, it overlaps strongly with one of the six proliferation resistance measures (Fissile Material Type) identified in the Proliferation Resistance and Physical Protection (PR\&PP) methodology [DOE 2006c], and it overlaps strongly with the material attractiveness criteria which are a key part of the DOE graded safeguards table [DOE 2006b]. Therefore, in the case of proliferation resistance, there are five other factors that need to be considered (technical difficulty, cost, time, detection probability, and detection resource efficiency). In the case of physical protection, there are two other factors that need to be considered (material quantity and security category).

With the above background on proliferation pathway stages and the material attractiveness figure of merit, we can modify the figure of merit for the particular situation of an orphaned surface storage facility, for each of three potential adversary objectives (on-site radionuclide dispersion, theft of material for later radionuclide dispersion, and theft of material for later processing and fabrication into a nuclear explosive). For example, King [2010] aggregates the FOM in the nuclear explosives fabrication stage 
with the number of SQs available for theft in the two nuclear systems he compared (a fusion-fission hybrid system deep-burning Pu in the subcritical blanket and a PWR burning MOX). King multiplies the FOM by a function that has a value of 1.0 for SQs above about 1.5 and that has a value of 0.0 for SQs below about 0.5 . This enabled the King study to show that, after 7 years of deep-burn irradiation time, the fusion-fission system is impractical to an adversary seeking to divert material for later processing and fabrication into a nuclear explosive.

The figure of merit, in turn, plays a role in the larger assessment of used fuel storage security being developed in this study. The modified figure of merit for each proliferation pathway stage and adversary objective is an integral part of the overall assessment. It can include some of the pertinent drivers and be integrated with other approaches to estimate other pertinent drivers.

\section{NEW REFERENCES}

Bathke, C. G., et al., 2009a. "An Assessment of the Attractiveness of Material Associated with a MOX Fuel Cycle from a Safeguards Perspective", Proc. of INMM 50 ${ }^{\text {th }}$ Annual Meeting, July 12 - 16, 2009, Tucson, Arizona.

Bathke, C. G., et al., 2009b. "The Attractiveness of Materials in Advanced Nuclear Fuel Cycles for Various Proliferation and Theft Scenarios", Proc. of Global 2009, September 6-11, 2009, Paris, France.

Cleary, V. D., et al., 2007. "Strengthening the Foundations of Proliferation Assessment Tools", Sandia National Laboratories, SAND2007-6158, Albuquerque, NM.

DOE, 2006c. "Evaluation Methodology for Proliferation Resistance and Physical Protection of Generation IV Nuclear Energy Systems, Revision 5," November 30, 2006. (www.gen-4.org/Technology/horizontal/PRPPEM.pdf).

King, W.E., et al., 2010. “The Application of a Figure of Merit for Nuclear Explosive Utility as a Metric for Material Attractiveness in a Nuclear Material Theft Scenario", Nuclear Engineering and Design, 240, pp. 3699-3707.

Sleaford, B. W., et al. 2010. "Nuclear Material Attractiveness: An Assessment of Material from PWR's in a Closed Thorium Fuel Cycle", ENC 2010, Barcelona, Spain.

\section{REFERENCES cited from the SNL draft report}

DOE, 2006b. "Material Control and Accountability," DOE M 470.4-6, Chg 1, U.S. Department of Energy, Washington DC. 